\title{
The rapid recognition of Lancefield group $B$ haemolytic streptococci
}

\author{
R. J. FALLON \\ From the Department of Laboratory Medicine, Ruchill Hospital, Glasgow
}

SYNOPSIS When grown overnight on Columbia agar in an atmosphere of hydrogen and carbon dioxide, haemolytic strains of Lancefield group B streptococci (Streptococcus agalactiae) produce orange or brown pigmented colonies. This production of pigmented colonies can be used for the rapid presumptive identification of these organisms as belonging to group B without the need for grouping by serological methods.

The production of pigmented colonies by streptococci has received little attention since first described by Orla Jensen (1919). He observed that red colouration was produced by several strains of pathogenic streptococci in casein peptone agar and noted that 'Streptococcus mastidis' (now known as Strep. agalactiae) formed an orange colour in casein peptone broth with added soluble starch. Durand and Giraud (1923) published a study of chromogenic streptococci in which they noted the importance of starch as a medium constituent and the maintenance of anaerobic conditions as factors necessary for the production of pigment. Eleven of the 125 strains they examined produced pigmented colonies including strains which were clearly pathogenic as well as some which they regarded as saprophytic. With one exception all strains came from human sources and appeared to be serologically related.

The isolation of a pigmented strain of streptococci from a case of pyelonephritis was reported by Olivieri (1929). Lancefield (1934) described studies on a strain of group B haemolytic streptococci which formed a yellow-brown pigment. In passing she commented that other strains produced pigment including nine of 29 strains classified in groups B and $D$ and that pigment was only apparent under conditions of partial or complete anaerobiasis.

Plummer (1941) in a study of 522 cultures of haemolytic streptococci found that 128 of 187 strains of group B produced pigment. Pigment production was also seen in one of four group D strains examined and noted in her table I (but not in the text of the paper) and in one of 28 strains which were not grouped. Apart from a passing reference by Esseveld,

Received for publication 14 August 1974.
Daniëls-Bosman, and Leijnse (1958) there appear to have been no other reports on this subject.

\section{Materials and Methods}

VAGINAL SWABS

These were taken with charcoal-impregnated cotto $8 \vec{\varphi}$ wool swabs and were transferred to the laboratory Stuart's (1959) transport medium.

\section{ORGANISMS}

In addition to strains isolated in this laboratory, cultures of the four serotypes of group B streptococci were kindly provided by $\mathrm{Dr} \mathrm{M}$. T. Parker; in addition non-haemolytic strains of group B were provided by $\mathrm{Dr}$ H. W. Wilkinson. These latter strains were described by Wilkinson, Thacker, and Facklam (1973).

\section{MEDIA}

The media used were Oxoid Columbia agar; blood agar made by adding $5 \%$ horse blood to Columbia agar base; Oxoid nutrient agar; and Oxoid nutrient broth.

\section{Results}

During the routine examination of blood agar plates inoculated with vaginal swabs from patients seen either for gynaecological or antenatal examination, it was noted that some plates contained haemolytic $\underset{2}{\sigma}$ colonies which were pink in appearance. On Gram 0 film examination of these colonies it was found that $\stackrel{D}{\mathbb{D}}$ they were streptococci. They did not appear to $\stackrel{?}{?}$ belong to serogroups $A, B, C, D, F$, or $G$ and hence 7 were forwarded to Dr M. T. Parker at the Central 902 
Public Health Laboratory, Colindale, for grouping. He reported that all the strains forwarded were of group B and included serotypes Ia, Ib, II, and III. Our failure to recognize them was due to using extraction with $0.2 \mathrm{~N} \mathrm{HCl}$ at $100^{\circ} \mathrm{C}$ instead of at $55^{\circ} \mathrm{C}$ in the Lancefield grouping technique. These apparently pink colonies were only seen on plates incubated anaerobically.

\section{PROOF OF PIGMENTATION}

An experiment was performed to confirm that the colonies were pigmented. A sterile Millipore membrane was placed on a blood agar plate and the streptococci were streaked across it. After overnight anaerobic incubation, orange pigmentation of the colonies was seen clearly against the white background of the membrane. No pigment was seen on aerobic incubation. The reason pigmentation had not been noted previously was not clear until it was realized that the recent introduction of the GasPak system of anaerobiasis into the laboratory may provide the explanation.

\section{CULTURAL CONDITIONS}

Cultures were set up and incubated at $37^{\circ} \mathrm{C}$ under the following conditions: (1) aerobically, (2) aerobically with $5-10 \% \mathrm{CO}_{2},(3)$ anaerobically in $\mathrm{H}_{2}$ with $\mathrm{CO}_{2}$ (GasPak system), (4) anaerobically in $\mathbf{H}_{2}$ alone, and (5) in $90 \% \mathrm{~N}_{2}$ and $10 \% \mathrm{CO}_{2}$. The results are shown in table I. Pigment was only produced overnight in cultures incubated in an atmosphere containing $\mathrm{CO}_{2}$ and was only consistently seen in cultures incubated in the jars containing $\mathrm{H}_{2}$ and $\mathrm{CO}_{2}$. This was probably because the anaerobiasis produced using $\mathrm{N}_{2}$ and $\mathrm{CO}_{2}$ was less complete than with $\mathrm{H}_{2}$ and $\mathrm{CO}_{2}$ as even using the latter system, if free gas exchange between the petri dish and the atmosphere in the jar was prevented by a film of moisture between the lid and the rim of the plate, pigment production was poor or absent.

\section{INFLUENCE OF CULTURE MEDIUM}

Blood was omitted from the medium and it was found that not only was pigment still produced after overnight incubation in $\mathrm{H}_{2}$ and $\mathrm{CO}_{2}$, but that

\begin{tabular}{ll}
\hline Atmosphere & Pigment Production \\
\hline Air & - \\
Air plus $5-10 \% \mathrm{CO}_{2}$ & - \\
Hydrogen & - \\
Hydrogen plus $\mathrm{CO}_{2}$ (Gaspak) & + \\
Nitrogen plus $10 \% \mathrm{CO}_{2}$ & \pm \\
\hline
\end{tabular}

Table I Effect of atmosphere on pigment production by group B haemolytic streptococci grown on Columbia agar it was much easier to see than on blood agar. Strains varied in the depth of colonial pigmentation from very pale orange to a deep orange-red colour. The impression was gained that some strains seemed able to produce much more pigment than others. Even the poor pigment-producing colonies were distinguishable from the white colonies produced by the same strains under aerobic conditions. The experiment was repeated using nutrient agar instead of Columbia agar but no pigment was formed after overnight incubation. As Columbia agar contains starch, $0 \cdot 1 \%$ soluble starch was added to nutrient agar and it was found that pigment was produced on this medium, although not as well as on Columbia agar. Hence, starch appeared to be a significant component of the medium. The observation of Lancefield (1934) that pigment was produced on plain agar containing less than $1 \%$ dextrose was not confirmed using Oxoid nutrient agar (table II). Unlike the observation of Plummer (1941) no pigment was seen in broth culture even in the presence of added starch

\begin{tabular}{ll}
\hline Medium & Pigment Production \\
\hline Columbia agar & ++ \\
Nutrient agar & - \\
Nutrient agar plus $1 \%$ dextrose & - \\
Nutrient agar plus $0.1 \%$ dextrose & - \\
Nutrient agar plus $0.1 \%$ starch & + \\
\hline
\end{tabular}

Table II Pigment production by group B haemolytic streptococci when grown in an atmosphere of $\mathrm{H}_{2}$ and $\mathrm{CO}_{2}$ on various media

\section{EFFECT OF MEDIUM PH ON PIGMENT PRODUCTION}

Occasionally batches of Columbia agar plates were encountered where pigment production by group B streptococci was poor. In order to investigate this, plates were prepared at different levels of $\mathrm{pH}$. Pigment production by colonies was poor on medium at $\mathrm{pH} 7$ but was easily seen at $\mathrm{pH} \mathbf{7 \cdot 3}$ or above. It is important, therefore, to ensure that the medium pH is not below $7 \cdot 3$.

EXAMINATION OF KNOWN GROUP B STRAINS Nineteen strains supplied by Dr M. T. Parker were examined. Seventeen of these were haemolytic and included serotypes Ia, Ib, II, and III. The results of examination for pigment production are shown in table III. Other non-haemolytic strains (Wilkinson et $a l, 1973)$ were also examined and the results are also shown in table III. It can be seen that nonhaemolytic strains consistently failed to produce pigment. 


\begin{tabular}{llll}
\hline & Serotype & No. of Strains & $\begin{array}{l}\text { No. Producing } \\
\text { Pigment }\end{array}$ \\
\hline Haemolytic & 1a & 1 & 1 \\
strains & 1b & 5 & 5 \\
& II & 6 & 6 \\
Non-haemolytic & III & 5 & 5 \\
strains & b & 8 & Nil \\
\hline
\end{tabular}

Table III Relationship between haemolytic properties and pigment production in group B streptococci

\section{Use in the Diagnostic Laboratory}

In view of these observations, all vaginal swabs were inoculated onto Columbia agar which was incubated in $\mathrm{H}_{2}$ and $\mathrm{CO}_{2}$ as well as onto the media in routine use in this laboratory. All $\beta$ haemolytic streptococci seen on the blood agar plates were grouped and the Columbia agar plates were examined for pigmented colonies. Where pigmented colonies occurred, they were present in virtually the same numbers as the haemolytic colonies on the blood agar plate inoculated from the same specimen except on the rare occasion when two different types of haemolytic colony were seen due to the presence of more than one group of streptococci in the specimen. When pigmented colonies were seen, they were always of group B. Over 120 strains of group B haemolytic streptococci so far examined produce pigmented colonies, whereas strains of haemolytic streptococci of groups $A, C, G$, and F isolated from vaginal swabs have consistently failed to produce pigment. None of 18 haemolytic strains of Strep. faecalis produced pigment.

A prospective study to determine what proportion of strains of group B haemolytic streptococci produce pigment gave the results shown in table IV.

\begin{aligned} & \hline No. of Strains Pigment Production on Primary Isolation \\ & \hline $54(85.7 \%)+ \\ & 9(14.3 \%)- \\ &$ Total 63 \\ & \hline\end{aligned}

Table IV Pigment production by group B haemolytic streptococci on primary isolation

It will be seen that some group B strains did not produce pigment on first isolation. This may have been due to the fact that they were unable to produce pigment, that the medium $\mathrm{pH}$ was unsatisfactory or that, where unvented plastic petri dishes were used, proper anaerobic conditions were not obtained due to moisture forming a seal between the plate lid and rim.

\section{Discussion}

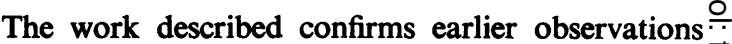
that group B streptococci frequently are able to $\overrightarrow{\vec{F}}$ produce pigmented colonies under anaerobic condi- $-\vec{O}$ tions in a medium containing starch. Pigment may be $\frac{C}{0}$ produced on other media without added starch $\overline{\bar{\omega}}$. either to a lesser extent, eg, Hartley digest agar as $\overparen{\mathbb{D}}$ made by the Streptococcal Reference Laboratory, 은 Colindale, or after a longer period of incubation so $\omega$ that the requirement of starch for pigment produc- $\overrightarrow{0}$ tion is probably relative rather than absolute. The $\overrightarrow{-}$ requirement for the presence of carbon dioxide has $\tilde{\sigma}_{\text {}}$ not previously been noted nor has the influence of pH on pigment production. The failure of non- $?$ haemolytic strains of group B streptococci to pro-. duce pigment agrees well with the observation of $\overrightarrow{ }$ Lancefield (1934) that when the strain of group B 8 streptococcus which she was investigating lost its $N$

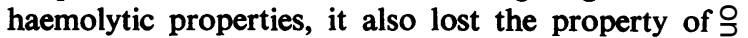
pigment production. Significantly, however, this strain did not lose its virulence so that it is unfortu- $z$ nate that the present system will not assist in the detection of non-haemolytic group B streptococci in situations where these may be acting as pathogens. Under the name of Strep. agalactiae group B streptococci have long been recognized as having pathe $\varphi$ genic potential being the cause of bovine mastitis (which may assume epidemic proportions). Following the description of group B by Lancefield (1933) occasional reports of the isolation of group B streptococci from human disease were made but it was not until the study of Hood, Janney, and Dameron (1961) was published that the significance of group $\vec{\overrightarrow{ }}$ B streptococci in perinatal morbidity and mortality in man was appreciated. Since that time other workers have confirmed and extended these findings (Eickhoff, 1972; Baker, Barrett, Gordon, and Yow, 1973; Barton, Reigin, and Lins, 1973; Franciosi, ? Knostman, and Zimmerman, 1973). It now seems that it is important to recognize group B streptococci from the human genital tract so that decisions may be taken regarding any action or surveillance to be undertaken on any given patient. The method 윽 described enables such recognition to be made easily $\rightarrow$ and rapidly without the need, in many instances, for time-consuming and expensive definitive serological N grouping of Strep. agalactiae. Hence, in routine diagnostic practice, a vaginal swab is inoculated onto $N$ a half plate of Columbia agar which is incubated $\mathbb{\omega}$ overnight in an atmosphere of $\mathrm{H}_{2}$ and $\mathrm{CO}_{2}$ together with a blood agar plate. If orange pigmented colonies $\varrho$ are seen on the Columbia agar plate and typical $\overparen{D}$ large, butyrous $\beta$ haemolytic colonies on the blood $\stackrel{?}{+}$ agar plate they can be identified presumptively as belonging to Lancefield's group B. If there are 
several types of haemolytic colony present it is naturally important to identify the strain not producing pigment by further examination using routine methods. The procedure can be applied to $\beta$ haemolytic streptococci isolated from other sites and in this instance many strains can be streaked on one Columbia agar plate, any pigmented strains being presumptively identified as group B.

Finally, it is important to note that the pigment may not be visible if plates are examined in fluorescent light. The pigment is best seen in daylight or in light from a tungsten filament lamp.

I wish to thank Dr M. T. Parker, for examining some of our group B strains, for providing strains of known serotype, and for supplying Hartley digest agar, and Miss E. P. Laird for secretarial assistance.

\section{References}

Baker, C. J., Barrett, F. F., Gordon, R. C., and Yow, M. D. (1973), Suppurative meningitis due to streptococci of Lancefield Group B: a study of 33 infants. J. Pediat., 82, 724-729.

Barton, L. L., Feigin, R. D., and Lins, R. (1973). Group B beta haemolytic streptococcal meningitis in infants. J. Pediat., 82, 719-723.
Durand, P., and Giraud, P. (1923). Les Streptocoques chromogènes. C.R. Acad. Sci. Paris, 177, 1333-1335.

Eickhoff, T. C. (1972). Group B streptococci in human infection. In Streptococci and Streptococcal Diseases: Recognition, Understanding and Management, edited by L. W. Wannamaker and J. M. Matsen, pp. 533-543. Academic Press, New York and London.

Esseveld, H., Daniëls-Bosman, M. S. M., and Leijnse, B. (1958). Some observations about the CAMP reaction and its application to human $\beta$ haemolytic streptococci. Antonie v. Leeuwenhoek, 24, 145-156.

Franciosi, R. A., Knostman, J. D., and Zimmerman, R. A. (1973). Group B streptococcal neonatal and infant infections. J. Pediat., 82, 707-718.

Hood, M., Janney, A., and Dameron, G. (1961). Beta haemolytic streptococcus Group B associated with problems of the perinatal period. Amer. J. Obstet. Gynec., 82, 809-18.

Lancefield, R. C. (1933). A serological differentiation of human and other groups of haemolytic streptococci. J. exp. Med., 57, 571595.

Lancefield, R. C. (1934). Loss of the properties of hemolysin and pigment formation without change in immunological specificity in a strain of Streptococcus haemolyticus. J. exp. Med., 59, 459. 469.

Olivieri, J. (1929). Note sur le streptocoque chromogène cause de pyélonéphrite chronique. J. Urol. Néphrol., 27, 484-491.

Orla Jensen, S. (1919). The Lactic Acid Bacteria, p. 116. Hest, Copenhagen.

Plummer, H. (1941). A serological and biochemical study of haemolytic streptococci. J. Immunol., 42, 91-107.

Stuart, R. D. (1959). Transport medium for specimens for public health bacteriology. Publ. Hlth Rep. (Wash.), 74, 431-438.

Wilkinson, H. W., Thacker, L. G., and Facklam, R. R. (1973). Nonhaemolytic Group B streptococci of human, bovine and ichthyic origin. Infect. and Immunol., 7, 496-498. 